\title{
МЕТОДИКА ОЦІНЮВАННЯ ЕФЕКТИВНОСТІ ФУНКЦІОНУВАННЯ СИСТЕМИ ЛОГІСТИЧНОГО ЗАБЕЗПЕЧЕННЯ СИЛ ОБОРОНИ ДЕРЖАВИ
}

Розвиток системи логістичного забезпечення завжди здійснювався паралельно з розвитком збройних сил $і$ способів ведення війни, операції (бою). Нові види озброєння та військової техніки, способи ведення бойових дій висували свої вимоги до системи логістичного забезпечення, змушували виробляти більш сучасні форми організачії системи логістичного забезпечення $і$ способи забезпечення військ. В ході проведеного автором статті дослідження розроблено методику оцінювання ефективності функціонування системи логістичного забезпечення сил оборони держави. Зазначена методика дозволяє оцінити ефективність функціонування системи логістичного забезпечення сил оборони держави та визначити ї̈ вплив на ефективність функиіонування бойових підрозділів сил оборони держави за кожним з напрямків забезпечення та завданням, щцо необхідно виконати; враховує важливість кожного з показників ефективності функціонування системи логістичного забезпечення сил оборони держави. За результатами проведеного дослідження автором було поставлено завдання на оцінку ефективності функиіонування системи логістичного забезпечення сил оборони держави.

Ключові слова: система логістичного забезпечення, сили оборони держави, ефективність, форми та способи.

\section{Вступ}

Враховуючи наявність об'єктивного чинника стримування реформування Збройних Сил України (ЗС України), типового в контексті теорії менеджменту змін (консервативність, опір змінам), необхідно визнати недостатність теоретичних розробок щодо оптимізації шляхів реформування ЗС України, передусім їх логістичного забезпечення.

Актуальність теми обраного дослідження обумовлена тенденціями розвитку сучасної воєннополітичної обстановки.

Збройна агресія Російської Федерації проти України стала довгостроковим чинником впливу на українську політичну, економічну, соціальну та військову реальність. Внаслідок дій Російської Федерації було деформовано систему глобальної та регіональної безпеки, а також чинну систему міжнародного права.

Окупація Криму і підтримка Російською Федерацією сепаратистських рухів у Луганській та Донецькій областях засвідчили хибність актуальних до недавнього часу оцінок воєнно-політичної обстановки, що склалася навколо України, а також внутрішніх та зовнішніх загроз національним інтересам держави. Згадані події спричинили, зокрема, необхідність термінового проведення оборонного огляду з метою забезпечення перегляду положень основних документів оборонного планування для спрямування наявних державних ресурсів на пріоритетні напрями розвитку Збройних Сил України з урахуванням зміни воєнно-політичної обстановки.

Російська загроза, що має довгостроковий характер, інші докорінні зміни у зовнішньому та внутрішньому безпековому середовищі України обумов- люють необхідність створення нової системи забезпечення національної безпеки України [1-10].

Тому існує необхідність у вирішені актуального наукового завдання, сутність якого полягає в формуванні ефективної логістичної системи Збройних Сил України.

Створення нової логістичної системи Збройних Сил України замість неефективної системи всебічного забезпечення військ (сил) стало поштовхом та актуальністю для даної роботи.

Сучасний етап розвитку логістики визначають два основні чинники: глобалізація світової економіки і інтенсивний розвиток науково-технічного прогресу, що породжують нові потреби споживачів в логістичних послугах і потребують розвитку різноманітних форм їх задоволення.

Одним з основних завдань логістичної системи $\epsilon$ мінімізація витрат, пов'язаних $з$ доведенням матеріального потоку від первинного джерела до кінцевого споживача.

Новий вигляд сучасних Збройних Сил України вимагає модернізації системи тилового та технічного забезпечення Збройних Сил України, зміст і суть якого повинні відповідати вимогам потреб Збройних Сил України при виконанні ними завдань за призначенням [11-14].

Таким чином, єдине ефективне функціонування логістичної системи Збройних Сил України становить актуальне завдання для органів військового управління, які організовують тилове та технічне забезпечення Збройних Сил України.

Логістичне забезпечення сил оборони під час виконання ними завдання з оборони держави, захисту іiі суверенітету, територіальної цілісності та недо- 
торканності організовується і здійснюється безперервно $з$ метою задоволення потреб складових сил оборони в озброєнні, військовій та спеціальній техніці, матеріально-технічних засобах, послугах та створення сприятливих умов для виконання ними завдань $з$ оборони держави.

Враховуючи зазначене, актуальним науковим завданням $\epsilon$ врахування максимальної кількості показників, за допомогою яких відбувається оцінювання системи логістичного забезпечення сил оборони держави та прогнозування іiі стану [6-14].

Метою зазначеної статті є розробка методики оцінювання ефективності функціонування системи логістичного забезпечення сил оборони держави.

\section{Виклад основного матеріалу}

Логістичне забезпечення сил оборони під час виконання ними завдання 3 оборони держави є основним видом забезпечення, що є основою бойової готовності і боєздатності військ для реалізації їх бойового потенціалу.

Вплив логістичного забезпечення на бойовий потенціал військ полягає в кількісно-якісній оцінці тактико-технічних характеристик (ТТХ) зразків озброєння та військової техніки (ОВТ), які перебувають на оснащенні підрозділів (частин та інших організаційно-штатних формувань).

Система логістичного забезпечення сил оборони держави є складовою сил оборони держави. Від ефективності системи логістичного забезпечення сил оборони держави напряму залежить ефективність функціонування сил оборони держави, в тому числі їх бойові потенціали.

Зазначена методика складається 3 наступної послідовності дій, що наведена на рис. 1 .

Дії 1-10 детально описані в наукових публікаціях автора, з якими можна ознайомитися в [15-16].

Під бойовим потенціалом зразка ОВТ слід розуміти інтегральний показник, що характеризує сукупність завдань, що виконуються зразком за цільовим призначенням (сукупність мінімаксних показників ТTX) за характерний час функціонування в усереднених розрахункових умовах [4-6]:

$$
Б \Pi_{a}=\frac{\sum_{n=1}^{N} T T X_{a_{n}} \cdot K_{n}}{\sum_{n=1}^{K} T T X_{E T_{n}} \cdot K_{n}},
$$

де $Б \Pi_{a}-$ бойовий потенціал $a$-го зразка ОВТ;

$n \in(1, N)$ - кількість параметрів, що визначають ТТХ $a$-го зразка ОВТ;

$T T X_{a_{n}}$ - мінімаксне значення параметра, що визначає $n$-ну ТТХ $a$-го зразка ОВТ;
$T T X_{E T_{n}}$ - мінімаксне значення параметра, що визначає $n$-ну ТТХ еталонного зразка ОВТ;

$K_{n}$ - ваговий коефіцієнт $n$-ї ТTХ, що характеризує їі вплив на реалізацію цільових перевірок призначення зразка ОВТ.

При цьому цільове призначення зразка ОВТ полягає в рішенні вогневих завдань з заданою ефективністю поразки об' єктів противника, логістичного забезпечення - реалізовувати бойовий потенціал за рахунок задоволення потреби в боєприпасах, пальному і інших видах логістичного забезпечення.

Бойовий потенціал військового формування (організаційно-штатного формування) - це інтегральний показник, що характеризує обсяг завдань за цільовим призначенням, який може виконати формування в розрахункових умовах при нормативних рівнях функціонування систем забезпечення (управління, всебічного забезпечення та підготовки особового складу):

$$
\begin{aligned}
& Б \Pi_{b}=\sum_{a=1}^{M} Б \Pi_{a} \cdot n_{a} \cdot \prod_{y=1}^{R} K_{b_{y}}^{\text {заб.норм }} \times \\
& \times K_{b}^{\text {упр.норм }} \cdot K_{b}^{\text {ос.норм }} \approx \sum_{a=1}^{M} Б \Pi_{a} \cdot n_{a},
\end{aligned}
$$

де $Б \Pi_{b}-$ бойовий потенціал $b$-го військового формування;

$a \in(1, M)$ - кількість різнотипних зразків ОВТ, які перебувають на озброєнні (оснащенні) в $b$-му військовому формуванні;

$Б \Pi_{a}$ - бойовий потенціал $a$-го зразка ОВТ;

$n_{a}$ - кількість зразків ОВТ $a$-го типу, які перебувають на озброєнні (оснащенні) в $b$-му військовому формуванні;

$y \in(1, R)$ - кількість підсистем, що забезпечують (окремих видів забезпечення системи логістичного забезпечення);

$K_{b_{y}}^{\text {заб.норм }} \rightarrow 1$ - коефіцієнт нормативної ефективності $y$-ї підсистеми забезпечення (виду забезпечення) $b$-го військового формування;

$K_{b}^{\text {упр.норм }} \rightarrow 1-$ коефіцієнт нормативної ефективності підсистеми управління $b$-го військового формування;

$K_{b}^{\text {ос.норм }} \rightarrow 1-$ коефіцієнт, що відображає нормативну ступінь кваліфікації особового складу $b$-го військового формування.

Система логістичного забезпечення $€$ і являє собою сукупність взаємопов'язаних органів військового управління, сил і засобів, що виконують завдання 3 логістичного забезпечення військ (сил) у мирний і воєнний час. 


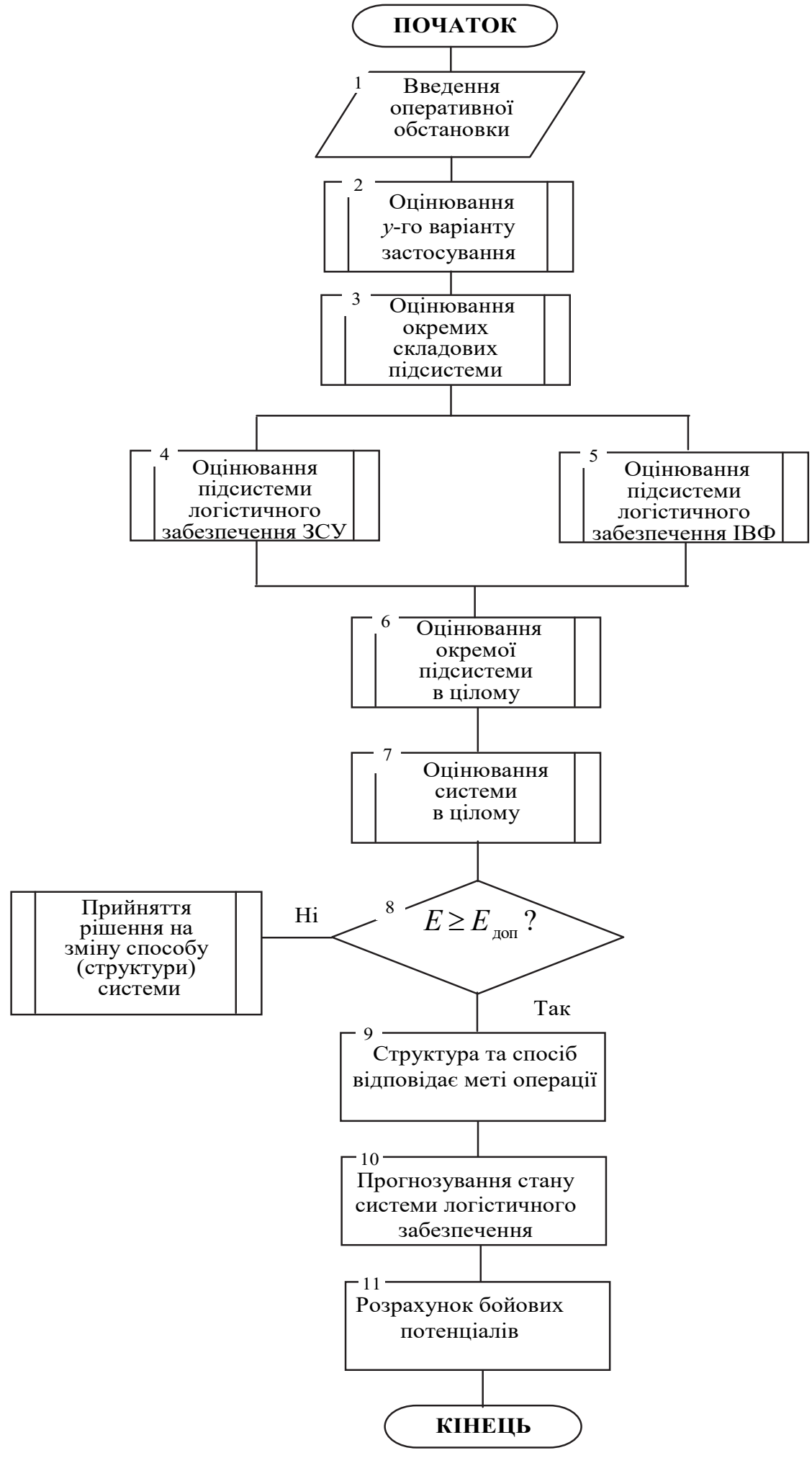

Рис. 1. Алгоритм реалізації запропонованої методики

Внесок системи логістичного забезпечення в реалізацію бойового потенціалу визначається завданнями, які вирішуються службами логістичного забезпечення [1-16]:

- планування логістичного забезпечення;

- визначення потреб в озброєнні, бойовій техніці, спеціальних і транспортних засобах та послугах;
- проектування, розроблення озброєння, військової та спеціальної техніки та матеріально-технічних засобів (МТЗ), їх закупівлі, постачання, зберігання, ремонту, технічного обслуговування, контролю експлуатації (використання);

- реалізації, списання та утилізації надлишкового озброєння, військової та спеціальної техніки і МТЗ; 
- планування та здійснення військових перевезень усіма видами транспорту;

- закупівлі робіт і послуг лазне-прального та торговельно-побутового обслуговування;

- організації харчування;

- розквартирування військ (сил, органів);

- закупівлі або будівництва, технічного обслуговування, експлуатації об’єктів військової інфраструктури.

Рішення перерахованих завдань покладається на служби логістичного забезпечення:

- продовольчу службу;

- речову службу;

- службу паливно-мастильних матеріалів.

3 урахуванням розв'язуваних пунктами логістичного забезпечення завдань аналітичний вираз бойового потенціалу має вигляд:

$$
\begin{gathered}
Б \Pi_{b}=\sum_{a=1}^{M} Б \Pi_{a} \cdot n_{a} \cdot \prod_{y=1}^{R} K_{b_{1}}^{n м \mu} \cdot K_{b_{2}}^{n p o д} . \\
\cdot K_{b_{3}}^{p e ч} \cdot K_{b_{4}}^{p a o},
\end{gathered}
$$

де $Б \Pi_{b}-$ бойовий потенціал $b$-го військового формування;

$a \in(1, M)$ - кількість різнотипних зразків ОВТ, які перебувають на озброєнні (оснащенні) в $b$-му військовому формуванні;

$Б \Pi_{a}-$ бойовий потенціал $a$-го зразка ОВТ;

$n_{a}$ - кількість зразків ОВТ $a$-го типу, які перебувають на озброєнні (оснащенні) в $b$-му військовому формуванні;

$$
y \in(1, R) \text { - кількість підсистем забезпення }
$$

(окремих видів забезпечення);

$K_{b_{1}}^{n м м}$ - коефіцієнт нормативної ефективності $y$-ї підсистеми забезпечення паливом $b$-го військового формування;

$K_{b_{2}}^{n р о д}$ - коефіцієнт нормативної ефективності підсистеми продовольчого забезпечення $b$-го військового формування;

$$
K_{b_{3}}^{\text {peч }} \text { - коефіцієнт нормативної ефективності }
$$

підсистеми речового забезпечення $b$-го військового формування;

$K_{b_{4}}^{\text {pao }}$ - коефіцієнт нормативної ефективності підсистеми забезпечення ракетно-артилерійським озброєнням $b$-го військового формування.

Для комплексної оцінки ефективності системи логістичного забезпечення використовуємо експертні методи.

Експертні методи застосовуються при виборі рішень, реалізованих в системі для вимірювання та оцінки одиничних показників, значення яких визна- чені розрахунковими, вимірювальним або аналітичним методами, для визначення показників і коефіцієнтів вагомості.

Якщо показник ефективності представити у вигляді сукупності властивостей, кожна 3 яких має відповідну одиницю вимірювання, то представлення будь-якої кількості окремих властивостей у вигляді безрозмірних показників робить ці властивості порівнянними з їх базовими значеннями:

$$
Y_{i}=\frac{N_{i}}{N_{i}^{\sigma a 3}} .
$$

Синтезований $з$ відібраних найбільш важливих одиничних показників комплексний показник ефективності повинен задовольняти наступній умові [3]:

$$
Y_{\text {комп }}=f\left(n_{1}, n_{2}, \ldots, n_{n}\right),
$$

де $n_{1}, n_{2}, \ldots, n_{n}-$ одиничні показники.

Для оцінки впливу одиничних показників необхідно агрегувати їх в комплексний показник ефективності, який представляє кількісну характеристику всіх його показників. Для його розрахунку може бути використана формула адитивної згортки одиничних показників [3]:

$$
Y_{\text {комп }}=\sum_{i=1}^{n} N_{i} \cdot K_{i}, \text { при умові } \sum_{i=1}^{n} N_{i}=1 \text {, }
$$

де $N_{i}$ - відносне значення $i$-го одиничного показника ефективності;

$K_{i}$ - вага (важливість) $i$-го одиничного показника в загальній системі показників.

Принцип призначення коефіцієнтів вагомості полягає в тому, що найбільш важливим, з точки зору експертів, показникам ефективності надаються великі значення вагових коефіцієнтів. Основне обмеження коефіцієнтів вагомості полягає в тому, що всі вони повинні бути позитивними числами. При використанні коефіцієнтів вагомості фактично вводиться спеціальна шкала для комплексної порівняльної оцінки. У такій шкалі відносна оцінка варіює в межах від нуля до позитивного числа, що дорівнює сумі всіх коефіцієнтів вагомості.

Добуток вагових властивостей одного рівня $є$ величина постійна [3]:

$$
\sum_{i=1}^{n} K_{i}=\text { const }
$$

Збільшення вагомості одного властивості може відбуватися за рахунок зменшення вагомості якихось інших властивостей цього ж рівня розгляду. Визначення коефіцієнтів вагомості проводиться експертним шляхом. Частоту повторення $i$-го одиничного показника розрахуємо за формулою [2]: 


$$
K_{i}=\frac{\sum_{i=1}^{n} K_{i j}}{\sum_{i=1}^{m} \sum_{j=1}^{n} K_{i j}},
$$

де $m$ - кількість експертів;

$n$ - кількість показників.

Аналіз узгодженості думок експертів за кількома чинниками, який впливає на один кінцевий результат (якість), оцінюється за допомогою коефіцієнта конкордації $W$, тобто загального коефіцієнта рангової кореляції для групи, що складається $3 \mathrm{~m}$ експертів [1; 7].

Коефіцієнт конкордації розраховується за формулою:

$$
W=\frac{12 S}{m^{2}\left(n^{3}-n\right)},
$$

де $S$-сума квадратів різниць між індивідуальними значеннями оцінок і середнім значенням.

Коефіцієнт конкордації змінюється від нуля до одиниці. Перевірка узгодженості думок експертів на невипадковість відбувається на основі критерію згоди Фішера. Задається рівень значущості ймовірності, нижче якого критерій згоди не буде відкидати гіпотезу про узгодженість думок експертів $(a=0,05)$. Критерій значущості обчислюється за формулою

$$
Z=\frac{0,5 \ln (m-1) W}{1-W} .
$$

\section{Висновки}

1. В зазначеній статті автором проведено розробку методики оцінювання ефективності функціонування системи логістичного забезпечення сил оборони держави.

2. Сутність зазначеної методики полягає в тому, що зазначена методика:

- дозволяє оцінити ефективність функціонування системи логістичного забезпечення сил оборони держави та визначити ії вплив на ефективність функціонування бойових підрозділів сил оборони держави за кожним з напрямків забезпечення та завданням, що необхідно виконати;

- враховує важливість кожного 3 показників ефективності функціонування системи логістичного забезпечення сил оборони держави.

3. В основу роботи зазначеної методики покладені математична модель прогнозування стану системи логістичного забезпечення сил оборони держави та інтегральний показник оцінки ефективності системи логістичного забезпечення сил оборони держави. Це дозволяє провести оцінку ефективності функціонування системи логістичного забезпечення та провести прогнозування іï стану на визначену кількість кроків вперед.

Напрямком подальших досліджень слід вважати оцінку ефективності функціонування системи логістичного забезпечення сил оборони держави.

\section{Список літератури}

1. Военно-экономический анализ / под ред. С.Ф. Викулова. - М.: Воениздат, 2000. - С. 31-34.

2. Наставление комитета начальника штабов JP 4-0. - 2013.

3. Всестороннее обеспечение (ADP 4-0 Sustainment). - 2019.

4. Полевой устав BC CША FM4-01.30 (FM 55-10). - 2003. - 276 c.

5. Шкурко Ю.М. Методический аппарат военно-экономического анализа мероприятий строительства вооруженных сил / Ю.М. Шкурко // Военная наука и оборонная политика. - 2003. - № 2. - С. 14-16.

6. Топоров А.В. Обоснование концептуальных подходов к оценке военно-экономической эффективности системы материально-технического обеспечения группировки войск (сил) / А.В. Топоров, В.И. Бабенков // Вопросы оборонной техники. Серия 16: Технические средства противодействия терроризму. - 2016. - № 9-10 (99-100). - С. 110-114.

7. Топоров А.В. Обоснование критериев оценки военно-экономической эффективности процессов материальнотехнического обеспечения войск (сил) / А.В. Топоров, В.И. Бабенков // Известия российской академии ракетных и артиллерийских наук. - 2017. - № 1(96). - С. 23-28.

8. Топоров А.В. Методологические основы военно-экономической эффективности интегрированной системы материально-технического обеспечения / А.В. Топоров, В.И. Бабенков // Известия российской академии ракетных и артиллерийских наук. - 2017. - № 4(99). - С. 13-22.

9. Топоров А.В. Обоснование военно-экономической эффективности процесса доставки материальных средств группировке войск (сил) / А.В. Топоров, В.Б. Коновалов, А.В. Бабенков // Известия российской академии ракетных и артиллерийских наук. - 2017. - № 2(97). - С. 48-51.

10. Бабенков В.И. Перспективные исследования военно-экономической эффективности материально-технического обеспечения войск / В.И. Бабенков, Д.С. Башкиров // Актуальные проблемы развития современной науки и образования: сборник международной научно-практической конференции. - 2017. - С. 112-113.

11. Бабенков А.В. Методологические подходы к военно-экономическому обоснованию и оценке параметров логистических процессов в системе материально-технического обеспечения войск / А.В. Бабенков // Известия российской академии ракетных и артиллерийских наук. - 2016. - № 1(91). - С. 25-31.

12. Гурьянов А.В. Концептуальные подходы адаптивного управления военно-промышленной безопасностью цепей поставок компонентов оборонно-промышленного комплекса / А.В. Гурьянов, В.И. Бабенков // Наука, образование, об- 
щество: тенденции и перспективы: сборник научных трудов по материалам международной научно-практической конференции. - 2017. - С. 94-96.

13. Гурьянов А.В. Военно-промышленная безопасность цепей поставок компонентов оборонно-промышленного комплекса / А.В. Гурьянов, В.И. Бабенков // Электронный научный журнал. - 2017. - № 7(22). - С. 72-75.

14. Калинин А.Н. Обоснование параметров оценки эффективности логистической системы обеспечения частной военной компании / А.Н. Калинин, М.Н. Козин // Современная наука: Актуальные проблемы теории и практики. Серия: Экономика и Право. - 2015. - № 11-12. - С. 29-33.

15. Наконечний О.В. Аналіз умов та факторів, що впливають на ефективність функціонування системи логістики сил оборони держав / О.В.Наконечний // Системи управління навігації та зв'язку. - 2019. - Вип. 3(55). - С. 48-57. https://doi.org/10.26906/SUNZ.2019.3.048.

16. Наконечний О.В. Інтегральний показник оцінки ефективності системи логістичного забезпечення сил оборони держави / О.В. Наконечний // Системи управління навігації та зв'язку. - 2019. - Вип. 6(58). - С. 71-74. https://doi.org/10.26906/SUNZ.2019.6.071.

\section{References}

1. Vikulov, S.F(2000). "Voyenno-ekonomicheskiy analiz"[ Military-economic analysis], Voenizdat, Moscow, pp. 31-34.

2. Department of the NAVY (2013), Instruction of the Chief of Staff Committee JP 4-0.

3. Department of the Army (2019), ADP 4-0 Sustainment.

4. United States Government US Army (2003), FM4-01.30 (FM 55-10), 276 p.

5. Shkurko, Yu.M. (2003), "Metodicheskiy apparat voyenno-ekonomicheskogo analiza meropriyatiy stroitel'stva vooruzhennykh sil" [The methodological apparatus of the military-economic analysis of the construction of the armed forces], Military Science and Defense Policy, No. 2, pp. 14-16.

6. Toporov, A.V. and Babenkov, V.I. (2016), "Obosnovaniye kontseptual'nykh podkhodov k otsenke voyennoekonomicheskoy effektivnosti sistemy material'no-tekhnicheskogo obespecheniya gruppirovki voysk (sil)" [Justification of conceptual approaches to assessing the military-economic efficiency of the system of material and technical support of a group of troops (forces)], Questions of Defense Technology. Series 16: Technical Means of Countering Terrorism, No. 9-10 (99-100), pp. 110-114.

7. Toporov, A.V. and Babenkov, V.I. (2017), "Obosnovaniye kriteriyev otsenki voyenno-ekonomicheskoy effektivnosti protsessov material'no-tekhnicheskogo obespecheniya voysk (sil)" [Justification of the criteria for assessing the militaryeconomic efficiency of the processes of material and technical support of troops (forces)], News of the Russian Academy of Rocket and Artillery Sciences, No. 1(96), pp. 23-28.

8. Toporov, A.V. and Babenkov, V.I. (2017), "Metodologicheskiye osnovy voyenno-ekonomicheskoy effektivnosti integrirovannoy sistemy material'no-tekhnicheskogo obespecheniya" [Methodological foundations of the military-economic efficiency of an integrated material and technical support system], News of the Russian Academy of Rocket and Artillery Sciences, No. 4(99), pp. 13-22.

9. Toporov, A.V., Konovalov, V.B. and Babenkov, A.V. (2017), "Obosnovaniye voyenno-ekonomicheskoy effektivnosti protsessa dostavki material'nykh sredstv gruppirovke voysk (sil)" [Justification of the military-economic efficiency of the process of delivering materiel to a grouping of troops (forces)], News of the Russian Academy of Rocket and Artillery Sciences, No. 2(97), pp. 48-51.

10. Babenkov, V.I. and Bashkirov, D.S. (2017), "Perspektivnyye issledovaniya voyenno-ekonomicheskoy effektivnosti material'no-tekhnicheskogo obespecheniya voysk" [Prospective studies of the military-economic efficiency of the material and technical support of the troops], Actual problems of the development of modern science and education: a collection of international scientific-practical conference, pp. 112-113.

11. Babenkov, A.V. (2016), "Metodologicheskiye podkhody k voyenno-ekonomicheskomu obosnovaniyu i otsenke parametrov logisticheskikh protsessov v sisteme material'no-tekhnicheskogo obespecheniya voysk" [Methodological approaches to the military-economic substantiation and estimation of parameters of logistic processes in the system of material and technical support of troops], News of the Russian Academy of Rocket and Artillery Sciences, No. 1(91), pp. 25-31.

12. Guryanov, A.V. and Babenkov, V.I. (2017), "Kontseptual'nyye podkhody adaptivnogo upravleniya voyennopromyshlennoy bezopasnost'yu tsepey postavok komponentov oboronno-promyshlennogo kompleksa" [Conceptual approaches of adaptive management of the military-industrial security of supply chains of components of the military-industrial complex], Science, education, society: trends and prospects: a collection of scientific papers on the materials of the international scientificpractical conference, pp. 94-96.

13. Guryanov, A.V. and Babenkov, V.I. (2017), "Voyenno-promyshlennaya bezopasnost' tsepey postavok komponentov oboronno-promyshlennogo kompleksa" [Military-industrial safety of supply chains of components of the military-industrial complex], Electronic Scientific Journal, No. 7(22), pp. 72-75.

14. Kalinin, A.N. and Kozin, M.N. (2015), "Obosnovaniye parametrov otsenki effektivnosti logisticheskoy sistemy obespecheniya chastnoy voyennoy kompanii" [Justification of parameters for assessing the effectiveness of the logistics system to ensure a private military company], Modern Science: Actual problems of theory and practice. Series: Economics and Law, No. 11-12, pp. 29-33.

15. Nakonechnyi, O.V. (2019), "Analiz umov ta faktoriv, shcho vplyvayut' na efektyvnist' funktsionuvannya systemy lohistyky syl oborony derzhav" [Analysis of conditions and factors affecting the effectiveness of the functioning of the system of logistics of the defense forces of the state], Control, Navigation and Communication Systems, No. 3(55), pp. 48-57. https://doi.org/10.26906/SUNZ.2019.3.048. 
16. Nakonechnyi, O.V. (2019), "Intehral'nyy pokaznyk otsinky efektyvnosti systemy lohistychnoho zabezpechennya syl oborony derzhavy" [Integral indicator of estimation of efficiency of the system of logistic support of the state defense forces], Control, Navigation and Communication Systems, No. 6(58), pp. 71-74. https://doi.org/10.26906/SUNZ.2019.6.071.

Надійшла до редколегії 15.01.2020

Схвалена до друку 11.02.2020

\section{Відомості про автора:}

\section{Наконечний Олександр Васильович \\ ад’юнкт}

Національного університету оборони України ім. І. Черняховського,

Київ, Україна

https://orcid.org/0000-0001-8854-8983

\section{Information about the author:}

\section{Oleksandr Nakonechnyi}

Doctoral Student

of the National Defence University of Ukraine named after Ivan Cherniakhovskyi,

Kyiv, Ukraine

https://orcid.org/0000-0001-8854-8983

\section{МЕТОДИКА ОЦЕНКИ ЭФФЕКТИВНОСТИ ФУНКЦИОНИРОВАНИЯ СИСТЕМЫ ЛОГИСТИЧЕСКОГО ОБЕСПЕЧЕНИЯ СИЛ ОБОРОНЫ ГОСУДАРСТВА}

А.В. Наконечный

Развитие системы логистического обеспечения всегда осуществлялось параллельно с развитием вооруженных сил и способов ведения войны, операции (боя). Новые виды вооружения и военной техники, способы ведения боевых действий выдвигали свои требования к системе логистического обеспечения, заставляли производить более современные формы организации системы логистического обеспечения и способы обеспечения войск. В ходе проведенного автором статьи исследования разработана методика оценки эффективности функционирования системы логистического обеспечения сил обороны государства. Указанная методика позволяет оценить эффективность функиионирования системы логистического обеспечения сил обороны государства и определить ее влияние на эффективность функиионирования боевых подразделений сил обороны государства по каждому из направлений обеспечения и задачам, которые необходимо выполнить; учитывает важность каждого из показателей эффективности функиионирования системы логистического обеспечения сил обороны государства. По результатам проведенного исследования автором была поставлена задача на оценку эффективности функиионирования системы логистического обеспечения сил обороны государства.

Ключевые слова: система логистического обеспечения, силь обороны государства, эффективность, формы и способы.

\section{METHODOLOGY FOR ESTIMATING THE EFFECTIVENESS OF FUNCTIONING A SYSTEM OF LOGISTIC SUP-PORT OF THE STATE DEFENSE FORCES}

O. Nakonechnyi

The experience of the history of wars and military conflicts shows that in each successfully conducted military company, operation (battle), as well as in every defeat, it is necessary, along with other reasons, to look for the positive and negative sides in the work of the logistic support bodies, their organization, capabilities and ways to use them. The development of the logistics support system has always been carried out in parallel with the development of the armed forces and methods of warfare, operations (combat). New types of weapons and military equipment, methods of warfare put forward their requirements for the logistics support system, forced to produce more modern forms of organization of the logistics support system and methods of providing troops. The system of logistic support of the state defense forces is a complex, multi-level structure. The aforementioned requires the search for new approaches to assess the effectiveness of the functioning of both the logistics support system itself and assess its impact on the effectiveness of the combat missions. In the course of the research conducted by the author of the article, a methodology was developed for assessing the effectiveness of the functioning of the system of logistics support for the state defense forces. The specified methodology allows us to evaluate the effectiveness of the functioning of the system of logistic support of the state defense forces and determine its impact on the effectiveness of the functioning of combat units of the state defense forces in each of the areas of support and tasks that must be completed; takes into account the importance of each of the indicators of the effectiveness of the functioning of the system of logistic support of the state defense forces. In the process of the research, the author used both general scientific and special research methods: semantic was used for the development of the essential part of the definitions of the categorical apparatus of military logistics; methods of economic analysis was used to assess trends in military support of the Armed Forces of Ukraine; system analysis methods were used to assess the prerequisites and the integration of goals in the process of forming a military logistics system; methods of economic and mathematical modeling was used to optimize the structure and internal processes of the military logistics system. Based on the results of the research, the author set the task to assess the effectiveness of the functioning of the system of logistic support of the state defense forces.

Keywords: logistics support system, state defense forces, efficiency, forms and methods. 